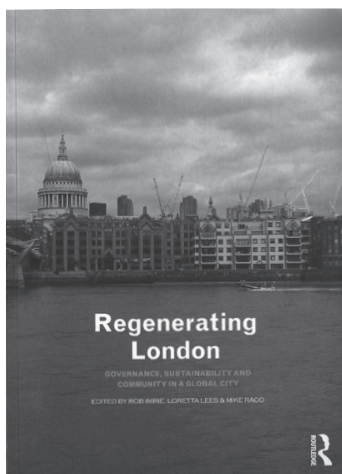

\title{
Regenerating London. GOVERNANCE, SUSTAINABILITY AND COMMUNITY IN A GLOBAL CITY
}

Editado por Rob Imrie, Loretta Lees y Mike Raco

NUEVA YORK: ROUTLEDGE, 2009

Regenerating London (353 páginas), sacado a circulación por Routledge en 2009 y cuyos editores son Rob Imrie, Loretta Lees y Mike Raco, aborda - tal como su nombre lo indica- varias de las facetas que ha tomado el proceso de regeneración urbana de la ciudad de Londres en los últimos treinta años, y que han llevado a esta ciudad desde ser una urbe en declinación a inicios de los ochenta, a la próspera y dinámica "ciudad global" de la actualidad. Es a partir de este cambio radical que los autores se preguntan sobre cuáles han sido los cambios que han posibilitado y que han resultado de este proceso de revitalización económica.

El objetivo principal de los autores es "proveer una visión académica, aunque accesible, de la regeneración urbana en Londres", en el entendido de que la capital británica es por su historia, su rol en la economía mundial (especialmente en la economía financiera) y su morfología, un actor especialmente interesante para el estudio de conceptos relacionados con la regeneración urbana, como gobernabilidad, gobernanza, comunidad, globalización y sustentabilidad. Plantean que estos dos últimos conceptos son especialmente relevantes para el debate académico sobre la regeneración urbana de los últimos años, tanto en Londres como en el resto del mundo. Así, el foco del libro está puesto en la discusión de proyectos de regeneración urbana que promuevan la inclusión social, que a su vez remite a la creación de lugares seguros, a la disminución de la polarización 
social y a la construcción de espacios que respondan a las necesidades de una población étnica y culturalmente diversa, como lo es la londinense.

El libro está dividido en cuatro partes de tamaño similar. La primera aborda las dimensiones del cambio urbano en la capital británica y está integrada a su vez por cuatro textos: "Regeneración de Londres" (R. Imrie, L. Lees y M. Raco), "Planificando Londres: una conversación con Peter Hall” (una entrevista de los editores al famoso planificador urbano inglés), "Regenerando una ciudad global” (T. Butler y C. Hamnett) y, finalmente, "Gobernando Londres: la evolución del paisaje institucional y de la planificación” (M. Tewdwr-Jones).

La segunda parte se refiere a los proyectos urbanos y a la idea de ciudad sustentable. Compuesta de cuatro capítulos ("Entendiendo el cambio urbano”, por M. Keith; “'Un ejemplo de ciudad sostenible': cambio urbano de tipo progresista y el desarrollo de King's Cross", por R. Imrie; “Gobierno local y la política de regeneración emblemática en Londres: el caso de Paddigton", por M. Raco y S. Henderson; y finalmente, "Los Juegos Olímpicos 2012 y la reconfiguración del este de Londres", por G. Poynter).

La tercera parte tiene por título Sustentabilidad, inclusión y mixtura social. Se compone de cuatro textos, que van desde el resurgimiento de los edificios de altura como modo de crecimiento urbano de tipo inclusivo y sustentable (R. Baxter y L. Lees), hasta el análisis de proyectos y programas de vivienda social desplegados para la regeneración de la capital británica (P. Watt), los que son mediados por otros dos capítulos, uno que aborda la red de canales alrededor del Támesis (M. Davidson) y otro dedicado al examen de los planes para hacer de Londres una ciudad caminable (J. Middleton).

La parte final del libro aborda la idea de gobernabilidad a nivel de la comunidad y el cambio urbano. En ella tienen cabida un artículo que examina los proyectos de regeneración de South Bank (G. Baeten), uno que estudia el cambio étnico en un mercado callejero del este de Londres (N. Dines), otro centrado en el mejoramiento de un council estate (conjunto de viviendas sociales) en Hackney (T. Manzi y K. Jacobs), y finalmente uno que estudia el comportamiento y las actitudes de jóvenes en diez condominios sociales del sector de King's Cross (N. Brown y L. Lees). El texto cierra con un capítulo de conclusiones a cargo de A. Cochrane.

El libro parte sosteniendo una doble tesis: que los procesos de regeneración urbana en la capital británica han sido escasamente abordados por la academia (la que, en cambio, ha documentado profusamente la historia de la ciudad); y que ellos han sido fruto fundamentalmente de intervenciones y acciones sobre el medio construido, las que han dado origen a múltiples geografías humanas.

Se sostiene que las políticas de regeneración urbana de los últimos treinta años en Londres, definidas como "las políticas y estrategias que han sido diseñadas para afrontar la declinación de la ciudad y la transformación social y económica de Londres", tienen tres aspectos comunes: han estado inmersas en políticas de desarrollo regional del sureste de Inglaterra, están muy relacionadas con la condición global de la ciudad y, por último, han sido exitosas en facilitar la regeneración cultural y económica de las zonas en que han sido aplicadas, pero esto no necesariamente se ha traducido en mayor igualdad entre sus habitantes, sino más bien lo contrario. 
Los autores sugieren que desde mediados de los ochenta, la regeneración urbana es vista como la estrategia más adecuada (si no la única), para la competitividad urbana. Llaman a esto la visión "globalista" de la regeneración urbana, que asume (de forma ingenua, según sus palabras) que la inserción en la economía mundial es la mejor medicina para muchos de los males de una sociedad. Tal idea estaría lejos de ser igualitaria, en el sentido de distribuir beneficios y recursos en forma homogénea en un país. Al contrario, a partir de ella se selecciona regiones, ciudades y áreas de ciudades "ganadoras" para la colocación de beneficios y recursos. Un ejemplo clásico de lo anterior es la región sureste del Reino Unido, donde se ubica Londres, que - en comparación con el resto del país - acumula una desproporcionada parte de riqueza. Lo propio ocurre con la misma ciudad, donde todas las áreas, a excepción del Este, han sido beneficiarias en mayor o menor medida de la pujanza de Londres.

Por otro lado, se plantea que a partir de los noventa, la naturaleza misma de las ciudades, y sobre todo de las ciudades globales como Londres, es la de estar cruzadas por múltiples grupos ciudadanos que operan tanto a nivel territorial como por intereses particulares. $\mathrm{Si}$ a ello se suma la existencia de problemas urbanos cada vez más complejos, que exigen la convergencia de agencias de distintos ministerios operando en distintas escalas, se tiene que la regeneración urbana es fundamentalmente un problema de gobernanza (más que de gobierno); es decir, de alineamiento de múltiples agendas en pos de un objetivo común, y especialmente de resolución de conflictos radicados en visiones contrapuestas sobre el fenómeno urbano. En este sentido, la regeneración urbana hoy requiere un rol activo de los ciudadanos, no solo porque estos son voces válidas y necesarias para la definición del tipo de ciudad que habitarán, sino también porque el producto final de las intervenciones urbanas de regeneración en Londres es la inserción de los ciudadanos en una economía global y competitiva.

Peter Hall plantea que esta condición - la participación ciudadana - ha sido la principal amenaza de los procesos de regeneración urbana a partir de los noventa: virtualmente ha paralizado la ciudad, haciendo mucho más difícil la modificación de cualquier paño urbano por las sucesivas rondas de negociaciones entre distintas agencias. Por último, Hall sostiene que, debido al proceso de cambio económico de Londres, en el cual las áreas centrales han sido gentrificadas casi en su totalidad, con excepción de algunos conjuntos de viviendas sociales (council estates), es recomendable que la provisión de vivienda económica se localice fuera de la ciudad, eso sí bajo estándares altos y en ubicaciones vecinas a corredores de transporte bien diseñados.

Desde el punto vista de su aporte al corpus teórico urbanístico, el libro tiene varias virtudes. En primer lugar, engloba una serie de procesos de distinta escala y naturaleza bajo un solo paraguas, el de regeneración urbana, y construye un marco interpretativo único para entender la evolución exitosa de una ciudad como Londres. Debido a que todos los textos tienen un cierto nivel de rigor investigativo (definen una pregunta de investigación, metodología para responderla y una hipótesis, y en general combinan metodologías cuantitativas y cualitativas), esta perspectiva no solo sirve para entender diversos procesos urbanos, sino también para evaluar las políticas que dieron origen a tales procesos.

Las deudas del libro van por dos lados. Pri- 
mero, existen textos (quizá tres) de calidad claramente inferior al resto o cuyo foco se aleja de la evaluación del impacto de un proyecto determinado de regeneración urbana y, en cambio, se limitan a comentar un tema en particular, a veces en forma exageradamente extensa. Un ejemplo de esto se encuentra en uno de los últimos capítulos, en que se analiza con exagerado detalle, y sin llegar a ninguna conclusión significativa, el fallido proceso de regeneración del mercado de Queens (al este de Londres), y cómo algunos vecinos, entre los cuales se cuenta al autor del texto, se opusieron a dicha empresa.

El segundo aspecto que llama la atención es la naturaleza última del término "regeneración”. Debido a que su uso abarca tanto la puesta en marcha de proyectos urbanos inmensos, como el Thames Gateway Project, que abarca más de 100 kilómetros de largo, como el de la construcción de edificios de altura en diversos lugares de Londres o el plan para hacer de la ciudad una más caminable, cabe preguntarse cuál es la línea divisoria entre un proyecto que se puede califi- car de regeneración urbana, y otro que no lo es. Después de todo, ¿acaso las intervenciones urbanas (tanto a escala residencial como de infraestructura urbana) no son mayoritariamente proyectos que, en mayor o menor medida, buscan la revitalización económica de la ciudad? La vaguedad con que es usado el término "regeneración urbana" no contribuye a aclarar estas dudas.

Con todo, el libro merece ser leído. Los textos en su conjunto muestran cómo una serie de iniciativas urbanas fragmentadas y sin mayor conexión aparente entre sí, en la práctica se influencian unas a otras (a veces complementándose; otras, anulándose), lo que lleva a preguntarse hasta qué punto las áreas metropolitanas requieren no solo de gobernanza, sino también de un gobierno. Así, el debate no parece reducirse a cómo garantizar el crecimiento económico con la participación ciudadana y la equidad, tal como lo plantean los autores al final, sino cómo articular un gobierno eficaz de la ciudad, capaz de articular proyectos de distinto tipo y escala de forma concreta, eficiente y democrática. CEURE

\section{Rodrigo Mora}

Universidad Diego Portales, Santiago, Chile.

E-MAIL: RODRIGO.MORA@UDP.CL 